\title{
The Relationship between Nasal Carriage of Staphylococcus aureus and Surgical Site Infections in a Hospital Center in Morocco
}

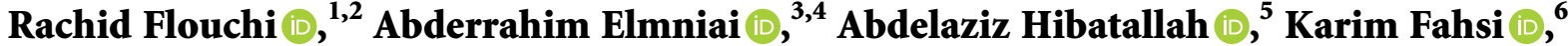 \\ Ibrahim Touzani $\left(\mathbb{D},{ }^{1}\right.$ and Kawtar Fikri-Benbrahim ${ }^{1}{ }^{1}$
}

${ }^{1}$ Laboratory of Microbial Biotechnology and Bioactive Molecules, Science and Technologies Faculty, Sidi Mohamed Ben Abdellah University, Fez, Morocco

${ }^{2}$ High Institute of Nursing Professions and Health Techniques Annex Taza, Fez, Morocco

${ }^{3}$ Human Pathology, Biomedicine and Environment Laboratory, Faculty of Medicine and Pharmacy, Sidi Mohamed Ben Abdellah University, Fez, Morocco

${ }^{4}$ Provincial Laboratory of Epidemiology and Environmental Hygiene, DMS, Taza, Morocco

${ }^{5}$ Surgical Department, Provincial Hospital Center Ibn Baja, Taza, Morocco

${ }^{6}$ High Institute of Nursing Professions and Health Techniques, Rabat, Morocco

Correspondence should be addressed to Kawtar Fikri-Benbrahim; kawtar.fikribenbrahim@usmba.ac.ma

Received 26 April 2021; Accepted 20 August 2021; Published 26 August 2021

Academic Editor: Rossella Grande

Copyright $(92021$ Rachid Flouchi et al. This is an open access article distributed under the Creative Commons Attribution License, which permits unrestricted use, distribution, and reproduction in any medium, provided the original work is properly cited.

Background. Surgical site infection is a major public health problem in the world. Nasal carriage is a major risk factor for the development of nosocomial Staphylococcus aureus infection, especially methicillin-resistant Staphylococcus aureus (MRSA). Our work aims to determine the prevalence of Staphylococcus aureus, methicillin-resistant Staphylococcus aureus, and the associated risk factors and to evaluate their sensitivity to 27 antibiotics. Methods. A cross-sectional study was carried out on 100 patients, hospitalized in preoperative care of surgery units at the Taza Provincial Hospital Center in the Fez-Meknes region, from January to June 2019. Samples were taken from the patient's anterior nostril using single-use sterile dry or wet cotton swabs and then analyzed in the Provincial Public Health Laboratory in Taza. The carriage of Staphylococcus aureus was studied by conventional bacteriological methods by spreading nasal swabs on Chapman culture medium, while antibiotic resistance was determined by the Mueller-Hinton agar disc diffusion method according to the recommendations described by the Antibiogram Committee of the French Society of Microbiology 2019 (CA SFM 2019). Results. Of the 84 patients found to be positive, $45.24 \%$ had coagulasepositive Staphylococcus aureus and $54.76 \%$ had coagulase-negative Staphylococcus. After surgery in the postoperative phase, 16 patients developed surgical site infections, of which two had a negative nasal culture and 14 had positive nasal culture. Among the Staphylococcus aureus-positive patients, $36.84 \%$ were colonized by a methicillin-resistant Staphylococcus aureus (MRSA) and $63.16 \%$ by a methicillin-sensitive Staphylococcus aureus (MSSA). Of these, 57.14\% of MRSA colonized patients developed an infection of the surgical site and $42.85 \%$ showed no sign of SSI, while for patients colonized by MSSA, $16.67 \%$ developed SSI and $83.33 \%$ showed no sign of SSI. Moreover, children were the most affected by MRSA. Concerning antibiotic sensitivity, multiresistance of MRSA to more than 3 antibiotics has been found. Conclusion. To the best of our knowledge, this is the first study carried out in this hospital center with the aim of knowing the prevalence of nasal carriage of Staphylococcus aureus and MRSA and to identify the risk factors in order to prevent infections related to nasal carriage of Staphylococcus aureus and MRSA. 


\section{Introduction}

Surgical site infections (SSIs) are infections that occur after surgery, 30 days postoperatively or one year postoperatively for prosthetic surgery procedures. These infections are classified as superficial, deep, organ, or space infections [1]. SSIs represent a concern for health systems because of their high mortality and morbidity rates, the increase in the average length of hospital stay, as well as expenses and costs, which increases the number of postoperative patients $[2,3]$ and reduces the care quality and the hospital's branding. SSIs are the second nosocomial infection occuring in France after urinary tract infections [3] and pose a major public health problem in Africa due to their incidence varying between $6.8 \%$ and $26 \%$ [4]. Staphylococcus aureus remains the most common cause of infections in operating sites [5].

In humans, the anterior nostrils of the nose are the most common sites of carriage for Staphylococcus aureus (S. aureus), which remains a well-defined risk factor for infection with this bacterium $[6,7]$. In a previous study on the role of nasal carriage in $S$. aureus infections, it has been shown that there is an increase in carriage rates in extranasal sites for nasal $S$. aureus carriers, for example, skin carriage on the hands increases from $27 \%$ in normal population to $90 \%$ in permanent nasal S. aureus carriers [6], which present in surgery cases a higher risk of nosocomial $S$. aureus infection (bacteremia) compared to controls [8].

Nasal carriage of $S$. aureus creates a major risk of SSI in carrier's patients, some of whom have a greater risk by carrying methicillin-resistant Staphylococcus aureus (MRSA), which is an additional risk factor for surgical site infection and has become endemic in some hospital areas [9]. In addition, the ineffectiveness of antibiotic prophylaxis on MRSA strains increases the risk of SSI with MRSA in patients treated in surgical intensive care units [10] in Morocco, where little research has been done on this subject. To this end, the objective of our investigation is to study the nasal carriage of Staphylococcus aureus and non-aureus in preoperative patients in a provincial hospital center and to study the antibiotic resistance of all strains isolated in order to determine their relationship with postoperative patients' surgical site infection.

\section{Materials and Methods}

2.1. Study Population. This is a cross-sectional prospective study which was conducted over a period of six months (January to June 2019) in a Provincial Hospital Center in Taza city (in Fez-Meknes region, in the northeast of Morocco). The study concerned patients hospitalized in preoperative care in the men's, women's, children's, and gynecological-obstetric surgery units. Concerning the inclusion criteria, patients hospitalized preoperatively, having benefited from a surgical intervention and being followed up postoperatively, were included in this study, while the patients who did not benefit from a surgical intervention were all excluded. The choice was made in an anarchic way according to patients who agreed to participate in the study.
Patients' medical records were reviewed and examined for demographic information: for information on the antibiotics prescription in the postoperative period and for the detection of surgical site infections.

2.2. Sampling Mode. Samples were taken using single-use sterile dry or moist cotton swabs which were inserted into the patient's anterior nostril $(1-2 \mathrm{~cm})$. Thereby, nasal secretions were collected by performing 5 complete rotations of the swab, the same swab being used for both nostrils [11]. Immediately after taking the samples, the swabs were sent directly in an isothermal box to the Provincial Public Health Laboratory in Taza, where they were spread on the Chapman medium and then incubated at $35^{\circ} \mathrm{C}( \pm 2)$ for 24 to 48 hours.

2.3. Bacteriological Analysis. The carrying of S. aureus was investigated by classical bacteriological methods by spreading nasal swabs on the Chapman culture medium (OXOÏD society). Colonies fermenting mannitol were suspected as Staphylococcus aureus; then, bacterial identification was based on morphological and biochemical characters: colonies appearance; mannitol's fermentation based on the strain's ability to use or not mannitol as carbon source; and DNAse positive, Gram positive, oxidase positive, and catalase negative activities. Hence, creamy colonies having a circular outline, a rounded shape, a smooth appearance, a convex elevation, and a viscous consistency are characteristic to $S$. aureus for which microscopic examination shows Gram-positive diplococci or cocci in regular clusters. Moreover, fermentation produces organic acids after sugar's degradation; the accumulation of these organic acids in the culture medium induces its acidification leading to a change of the phenol red ( $\mathrm{pH}$ indicator) to yellow. Furthermore, DNase tests are conducted on a DNA agar medium, after 18 to 24 hours of incubation, the presence of a clear area around the streaks indicates the presence of DNase activity.

Finally, the strain's confirmation is carried out on an $\mathrm{API}^{\circledR} 20$ Staph gallery (bioMérieux company) made up of 20 microtubes containing dehydrated substrates. The microtubes are inoculated with a bacterial suspension prepared on the API Staph medium. The reactions produced during the incubation period result in spontaneous color changes or are revealed by the addition of specific reagents; then, identification is made using the analytical catalog. The identified strains were stored at $-18^{\circ} \mathrm{C}$.

2.4. Sensitivity to Antibiotics. Antibiotic resistance was determined by the Mueller-Hinton agar disc diffusion method according to the recommendations described by the Antibiogram Committee of the French Society of Microbiology 2019 (CA SFM 2019) [12]. The Mueller-Hinton medium was inoculated by swabbing pure bacterial strains of Staphylococcus aureus and incubated $18-24$ hours at $37^{\circ} \mathrm{C}$, after placing antibiotic discs (BIOANALYSE®) society). The antibiotic discs used with their respective load are as follows: amikacin $(30 \mu \mathrm{g})$; amoxicillin $(25 \mu \mathrm{g})$; amoxicillin + clavulanic 
acid $(10 \mu \mathrm{g})$; ceftazidime $(30 \mu \mathrm{g})$; cefixime $(10 \mu \mathrm{g})$; ceftriaxone $(30 \mu \mathrm{g})$; chloramphenicol $(30 \mu \mathrm{g})$; ciprofloxacin $(5 \mu \mathrm{g})$; cefalexin $(30 \mu \mathrm{g})$; cefoxitin $(30 \mu \mathrm{g})$; cefotetan $(30 \mu \mathrm{g})$; cefotaxime $(30 \mu \mathrm{g})$; cefalotin $(30 \mu \mathrm{g})$; erythromycin $(15 \mu \mathrm{g})$; fusidic acid $(10 \mu \mathrm{g})$; imipenem $(10 \mu \mathrm{g})$; lincomycin $(15 \mu \mathrm{g})$; nalidixic acid $(30 \mu \mathrm{g})$; ofloxacin $(5 \mu \mathrm{g})$; oxacillin $(5 \mu \mathrm{g})$; piperacillin $(30 \mu \mathrm{g})$; rifampicin $\quad(30 \mu \mathrm{g}) ; \quad$ trimethoprim + sulfamethoxazole $(1.25 \mu \mathrm{g})$; tetracycline $(30 \mu \mathrm{g})$; ticarcillin $(75 \mu \mathrm{g})$; tobramycin $(30 \mu \mathrm{g})$; and teicoplanin $(30 \mu \mathrm{g})$.

The antibiogram reading was done according to the recommendations of CA SFM 2019 [12], and the inhibition diameters were measured manually using a graduated ruler. Hence, methicillin resistance was determined by the diffusion method of the cefoxitin disc, and an inhibition diameter around this disc of less than $22 \mathrm{~mm}$ indicates the suspicion of the presence of a methicillin-resistant Staphylococcus aureus strain.

2.5. Statistical Analysis. Data were analyzed using SPSS and Microsoft Office Excel 2010. The $p$ values for the variables analyzed in each case were calculated by the Fisher's exact test and the chi ${ }^{2}$ test, considering $p$ value $<0.001$ as highly significant, $p$ value $<0.01$ as very significant, and $p$ value $<0.05$ as significant.

\section{Results}

For a total of 100 patients, $25 \%$ for each service, the mean age of 39 years ( \pm 1 year) and sex ratio of 1.22 have been registered. In the preoperative period, $84(84 \%)$ patients have had positive nasal cultures and $16 \%(n=16)$ have had negative nasal cultures. Of the 84 patients revealed positive, $45.24 \%(n=38)$ has had a coagulase-positive Staphylococcus aureus, and $54.76 \%(n=46)$, a coagulase-negative Staphylococcus (Table 1).

In the postoperative phase, 16 patients have presented surgical site infections, among which 2 patients have had negative nasal culture and 14 have had positive nasal culture (12 patients with Staphylococcus aureus and 2 patients with coagulase-negative Staphylococcus).

Among the Staphylococcus aureus-positive patients, 14 (36.84\%) have been colonized with methicillin-resistant Staphylococcus aureus (MRSA) and 24 (63.16\%) have been colonized with methicillin-sensitive Staphylococcus aureus (MSSA). Of these, 8 MRSA colonized patients have developed an operative site infection (SSI) (57.14\%) and 6 have shown no signs of SSI (42.85\%), and for MSSA colonized patients, $4(16.67 \%)$ have developed an SSI and 20 (83.33\%) have shown no signs of SSI (Figure 1).

For the most affected departments (Table 1), the gynecology department have been the most affected with 12 patients colonized by Staphylococcus aureus (31.57\%), followed by children's surgery $(n=11 ; 28.95 \%)$, women's surgery $(n=09 ; 23.69 \%)$, and men's surgery $(n=06 ; 15.79 \%)$, respectively. The age group most affected by S. aureus has been the group between 30 and 45 years old with 13 cases (34.22\%), followed by the group under 15 years old with 11 cases $(28.95 \%)$, and then 8 people over 45 years old $(21.04 \%)$.
Females have been the most carriers of $S$. aureus with a rate of $63.16 \%$. Moreover, patients admitted to the programmed surgery are the most colonized by $S$. aureus with 20 cases $(52.63 \%)$, as well as patients with no venous catheters and patients not presenting any associated pathology are the most affected by S. aureus.

Concerning specialties, gynecology has recorded the highest number of $S$. aureus infections, followed by pediatric surgery, orthopedic surgery, visceral surgery, and urology. However, these infections have been absent in otolaryngology surgery and neurosurgery. Otherwise, patients from rural areas have been the main carriers of $S$. aureus with a percentage of $65.78 \%$ compared to urban patients. For services, where operative site infection was developed, the children's surgeries service has ranked first with 5 cases (41.66\%) followed by gynecology (3 cases) $(25.00 \%)$ and then women's and men's surgeries having the same cases number ( 2 cases in each surgey unit corresponding to 16.67\%) (Table 1).

Regarding the regression analysis between $S$. aureus and patient characteristics (Table 1), the rate of $S$. aureus carriers has been found statistically insignificant in relation to services, age, sex, venous catheter, and pathologies associated with the specialty and origin $(p>0.05)$. However, a highly significant relationship has been noted between $S$. aureus carriers and surgical site infections, $p=0.007(p<0.01)$, odds ratio at the $95 \%$ confidence interval, $\mathrm{OR}=4.2391$ [1.3016; 15.3893], as well as a significant relationship between $S$. aureus carriers and the nature of admission to services, $p=0.01$, odds ratio at the $95 \%$ confidence interval, $\mathrm{OR}=3.0483$ [1.181; 8.0862].

In relation to MRSA colonized patients (Table 2), the children's surgery department has the highest number of patients ( 5 cases $(35.71 \%))$, followed by men's surgery (4 cases $(28.58 \%))$, then gynecology (3 cases $(21.43 \%))$ and women's surgery (2 cases $(14.28 \%))$. Regarding the age group, most colonized with MRSA, it is under 15 years old (35.71\%), while the carriers of MSSA are between 30 and 45 years old (37.50\%). Moreover, females are the most affected by MRSA (64.29\%), as well as patients admitted in emergency, venous catheter carriers, and also patients without associated pathologies. For the specialty, children's surgery is at the first level (with 5 cases of MRSA) followed by gynecology and orthopedic surgery (3 cases for each one), then visceral (2 cases), and urology (1 MRSA carrier case). Patients from rural areas are the most colonized by MRSA (78.57\%). For the services affected by MRSA whose patients developed an SSI, child surgery (37.5\%) is followed by gynecology and men's surgery (25\%) and finally women's surgery $(12.5 \%)$.

Concerning the regression analysis between MRSA and patient characteristics (Table 2), MRSA has been found statistically nonsignificant in relation to services, age, sex, venous catheter, and pathologies associated with the specialty and origin $(p>0.05)$, but a significant relationship has been reported between MRSA carriers and surgical site infections, $p=0.04(p<0.05)$, odds ratio at $95 \%$ confidence interval, $\mathrm{OR}=4.908[0.9553 ; 34.6181]$, and also between MRSA carriers and the nature of admission to services, $p=$ 
TABLE 1: Demographic and clinical characteristics of patients by nasal carriage status of Staphylococcus aureus $(N=100)$.

\begin{tabular}{|c|c|c|c|c|}
\hline $\begin{array}{l}\text { Demographic and clinical } \\
\text { characteristics of patients }\end{array}$ & $\begin{array}{c}\text { Carriers of Staphylococcus } \\
\text { aureus, } n=38\end{array}$ & $\begin{array}{c}\text { Noncarriers of Staphylococcus } \\
\text { aureus, } n=62\end{array}$ & $\begin{array}{l}\text { OR confidence interval } \\
\text { at } 95 \%\end{array}$ & $\begin{array}{c}p \\
\text { value }\end{array}$ \\
\hline $\begin{array}{l}\text { Services } \\
\text { Women's surgery } \\
\text { Men's surgery } \\
\text { Gynecology } \\
\text { Child surgery }\end{array}$ & $\begin{array}{c}9(23.69 \%) \\
6(15.79 \%) \\
12(31.57 \%) \\
11(28.95 \%)\end{array}$ & $\begin{array}{l}16(25.80 \%) \\
19(30.65 \%) \\
13(20.97 \%) \\
14(22.58 \%)\end{array}$ & - & 0.86 \\
\hline $\begin{array}{l}\text { Age } \\
<15 \text { years } \\
15-30 \\
30-45 \\
45-60 \\
>60 \text { years old }\end{array}$ & $\begin{array}{c}11(28.95 \%) \\
6(15.79 \%) \\
13(34.22 \%) \\
4(10.52 \%) \\
4(10.52 \%) \\
\end{array}$ & $\begin{array}{c}14(22.58 \%) \\
9(14.52 \%) \\
10(16.12 \%) \\
11(17.74 \%) \\
18(29.04 \%) \\
\end{array}$ & - & 0.08 \\
\hline $\begin{array}{l}\text { Sex } \\
\text { Male } \\
\text { Female } \\
\end{array}$ & $\begin{array}{l}14(36.84 \%) \\
24(63.16 \%) \\
\end{array}$ & $\begin{array}{l}31(50 \%) \\
31(50 \%)\end{array}$ & $0.5865[0.2335 ; 1.4353]$ & 0.22 \\
\hline $\begin{array}{l}\text { Admission } \\
\text { Emergency } \\
\text { Programmed }\end{array}$ & $\begin{array}{l}18(47.37 \%) \\
20(52.63 \%) \\
\end{array}$ & $\begin{array}{c}14(22.58 \%) \\
48(77.42 \%) \\
\end{array}$ & $3.0483[1.181 ; 8.0862]$ & 0.01 \\
\hline $\begin{array}{l}\text { Venous catheter } \\
\text { Yes } \\
\text { No }\end{array}$ & $\begin{array}{l}16(42.11 \%) \\
22(57.89 \%) \\
\end{array}$ & $\begin{array}{l}24(38.71 \%) \\
38(61.29 \%) \\
\end{array}$ & $1.1499[0.4646 ; 2.8274]$ & 0.83 \\
\hline $\begin{array}{l}\text { Associated pathology } \\
\text { Yes } \\
\text { No }\end{array}$ & $\begin{array}{c}5(13.16 \%) \\
33(86.84 \%)\end{array}$ & $\begin{array}{c}12(19.36 \%) \\
50(80.64 \%)\end{array}$ & $0.6341[0.1598 ; 2.1613]$ & 0.58 \\
\hline $\begin{array}{l}\text { Duration of hospitalization } \\
\leq 24 \mathrm{~h} \\
\geq 24 \mathrm{~h}\end{array}$ & $\begin{array}{l}12(31.57 \%) \\
26(68.42 \%)\end{array}$ & $\begin{array}{l}21(33.87 \%) \\
41(66.13 \%)\end{array}$ & $0.524[0.1758 ; 1.4406]$ & 0.25 \\
\hline $\begin{array}{l}\text { Specialty } \\
\text { Child surgery } \\
\text { Gynecology } \\
\text { Orthopedic surgery } \\
\text { Visceral } \\
\text { Urology } \\
\text { Otolaryngology surgery } \\
\text { Neurosurgery }\end{array}$ & $\begin{array}{c}11(28.95 \%) \\
12(31.58 \%) \\
8(21.06 \%) \\
5(13.15 \%) \\
2(5.26 \%) \\
- \\
- \\
\end{array}$ & $\begin{array}{c}14(22.58 \%) \\
13(20.97 \%) \\
16(25.80 \%) \\
9(14.52 \%) \\
6(9.67 \%) \\
2(3.23 \%) \\
2(3.23 \%) \\
\end{array}$ & - & 0.726 \\
\hline $\begin{array}{l}\text { Provenance } \\
\text { Urban } \\
\text { Rural }\end{array}$ & $\begin{array}{l}13(34.22 \%) \\
25(65.78 \%)\end{array}$ & $\begin{array}{l}26(41.94 \%) \\
36(58.06 \%)\end{array}$ & $0.7224[0.2829 ; 1.7946]$ & 0.52 \\
\hline $\begin{array}{l}\text { SSI } \\
\text { Yes } \\
\text { Women's surgery } \\
\text { Men's surgery } \\
\text { Gynecology } \\
\text { Child surgery } \\
\text { No } \\
\text { Women's surgery } \\
\text { Men's surgery } \\
\text { Gynecology } \\
\text { Child surgery }\end{array}$ & $\begin{array}{c}12(31.58 \%) \\
2(16.67 \%) \\
2(16.67 \%) \\
3(25.00 \%) \\
5(41.66 \%) \\
26(68.42 \%) \\
7(26.92 \%) \\
4(15.39 \%) \\
9(34.62 \%) \\
6(23.07 \%)\end{array}$ & $\begin{array}{c}6(9.68 \%) \\
1(16.67) \\
2(33.33) \\
1(16.67) \\
2(33.33) \\
56(90.32 \%) \\
15(26.78 \%) \\
17(30.36 \%) \\
12(21.43 \%) \\
12(21.43 \%)\end{array}$ & $\begin{array}{l}4.2391[1.3016 \\
\quad 15.3893]\end{array}$ & 0.007 \\
\hline
\end{tabular}

$0.014(p<0.05)$, odds ratio at $95 \%$ confidence interval, $\mathrm{OR}=6.2793$ [1.1926; 39.9359].

Regarding the antibiotic resistance profile (Table 3), out of the 38 Staphylococcus aureus isolated strains, 14 have shown total resistance to cefoxitin (MRSA), cefotaxime, and ticarcillin, while MRSA has shown strong resistance to amoxicillin + clavulanic acid (57.14\%), amoxicillin (64.29\%), ceftazidime $(85.72 \%)$, ceftriaxone $(78.58 \%)$, erythromycin
(64.29\%), cephalothin (85.72\%), nalidixic acid (57.15\%), oxacillin (92.86\%), piperacillin (78.58\%), and teicoplanin (85.73\%). Furthermore, MRSA has shown a total sensitivity to amikacin, chloramphenicol, ciprofloxacin, cefalexin, imipenem, lincomycin, ofloxacin, rifampicin, trimethoprimsulfamethoxazole, and tetracycline and also showed a high sensitivity to cefotetan (85.71\%), fusidic acid (78.57\%), and tobramycin (85.71\%), while MSSA has shown a slight 


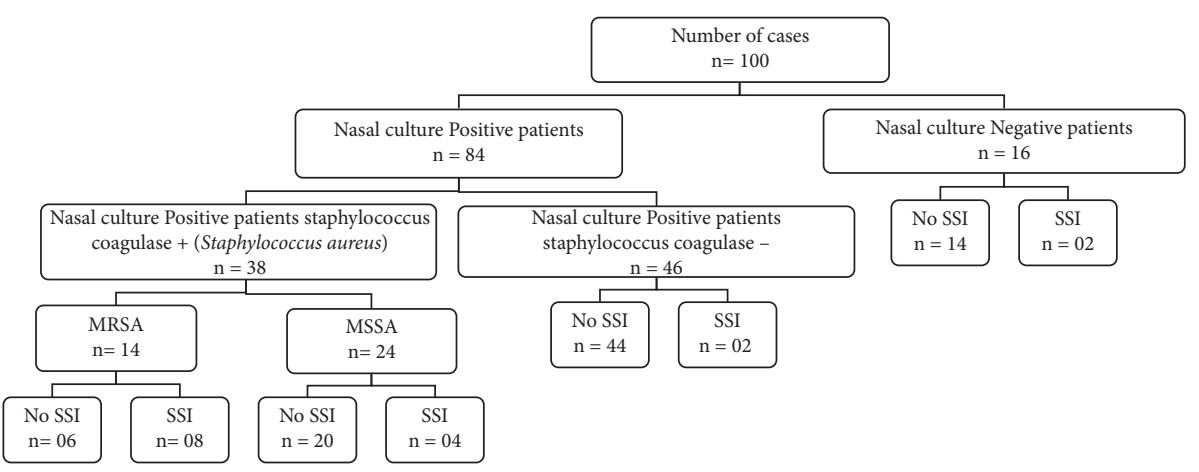

FIGURE 1: Flowchart of patient distribution according to Staphylococcus colonization.

TABLE 2: Demographic and clinical characteristics of patients by nasal carriage status of MRSA and MSSA $(N=38)$.

\begin{tabular}{|c|c|c|c|c|}
\hline \multirow[t]{2}{*}{ Demographic and clinical characteristics of patients } & \multicolumn{2}{|c|}{$\begin{array}{c}\text { Carriers of Staphylococcus } \\
\text { aureus, } n=38\end{array}$} & \multirow[t]{2}{*}{ OR confidence interval at $95 \%$} & \multirow[t]{2}{*}{$p$ value } \\
\hline & MRSA, $n=14$ & MSSA, $n=24$ & & \\
\hline $\begin{array}{l}\text { Services } \\
\text { Surgery for women } \\
\text { Surgery for men } \\
\text { Gynecology } \\
\text { Child surgery } \\
\end{array}$ & $\begin{array}{l}2(14.28 \%) \\
4(28.58 \%) \\
3(21.43 \%) \\
5(35.71 \%) \\
\end{array}$ & $\begin{array}{l}7(29.16 \%) \\
3(12.50 \%) \\
8(33.34 \%) \\
6(25.00 \%) \\
\end{array}$ & - & 0.46 \\
\hline $\begin{array}{l}\text { Age } \\
<15 \text { years } \\
15-30 \\
30-45 \\
45-60 \\
>60 \text { years old } \\
\end{array}$ & $\begin{array}{l}5(35.71 \%) \\
2(14.29 \%) \\
4(28.57 \%) \\
2(14.29 \%) \\
1(07.14 \%) \\
\end{array}$ & $\begin{array}{l}6(25.00 \%) \\
4(16.67 \%) \\
9(37.50 \%) \\
2(08.33 \%) \\
3(12.50 \%) \\
\end{array}$ & - & 0.91 \\
\hline $\begin{array}{l}\text { Sex } \\
\text { Male } \\
\text { Female } \\
\end{array}$ & $\begin{array}{l}5(35.71 \%) \\
9(64.29 \%) \\
\end{array}$ & $\begin{array}{c}9(37.5 \%) \\
15(62.5 \%) \\
\end{array}$ & $0.9278[0.1826 ; 4.3863]$ & 1 \\
\hline $\begin{array}{l}\text { Admission } \\
\text { Emergency } \\
\text { Programmed }\end{array}$ & $\begin{array}{c}11(78.57 \%) \\
3(21.43 \%) \\
\end{array}$ & $\begin{array}{l}10(41.67 \%) \\
14(58.33 \%) \\
\end{array}$ & $4.908[0.9553 ; 34.6181]$ & 0.04 \\
\hline $\begin{array}{l}\text { Venous catheter } \\
\text { Yes } \\
\text { No }\end{array}$ & $\begin{array}{l}8(57.14 \%) \\
6(42.86 \%) \\
\end{array}$ & $\begin{array}{l}11(45.83 \%) \\
13(54.17 \%) \\
\end{array}$ & $1.5569[0.3458 ; 7.3666]$ & 0.73 \\
\hline $\begin{array}{l}\text { Associated pathology } \\
\text { Yes } \\
\text { No }\end{array}$ & $\begin{array}{c}3(21.43 \%) \\
11(78.57 \%) \\
\end{array}$ & $\begin{array}{c}4(16.67 \%) \\
20(83.33 \%) \\
\end{array}$ & $1.3522[0.1672 ; 9.6891]$ & 1 \\
\hline $\begin{array}{l}\text { Hospitalization duration (preoperative) } \\
\leq 24 \mathrm{~h} \\
\geq 24 \mathrm{~h} \\
\end{array}$ & $\begin{array}{c}4(25.57 \%) \\
10(71.42 \%) \\
\end{array}$ & $\begin{array}{l}11(45.83 \%) \\
13(54.17 \%) \\
\end{array}$ & $0.4821[0.0853 ; 2.3066]$ & 0.32 \\
\hline $\begin{array}{l}\text { Specialty } \\
\text { Child surgery } \\
\text { Gynecology } \\
\text { Orthopedic surgery } \\
\text { Visceral } \\
\text { Urology } \\
\end{array}$ & $\begin{array}{l}5(35.71 \%) \\
3(21.43 \%) \\
3(21.43 \%) \\
2(14.29 \%) \\
1(07.14 \%) \\
\end{array}$ & $\begin{array}{l}6(25.00 \%) \\
8(33.34 \%) \\
6(25.00 \%) \\
3(12.50 \%) \\
1(04.16 \%) \\
\end{array}$ & - & 0.92 \\
\hline $\begin{array}{l}\text { Provenance } \\
\text { Urban } \\
\text { Rural }\end{array}$ & $\begin{array}{c}3(21.43 \%) \\
11(78.57 \%)\end{array}$ & $\begin{array}{l}10(41.67 \%) \\
14(58.33 \%)\end{array}$ & $0.3913[0.0556 ; 2.0501]$ & 0.29 \\
\hline SSI & & & & \\
\hline
\end{tabular}


TABle 2: Continued.

\begin{tabular}{|c|c|c|c|c|}
\hline \multirow[t]{2}{*}{ Demographic and clinical characteristics of patients } & \multicolumn{2}{|c|}{$\begin{array}{c}\text { Carriers of Staphylococcus } \\
\text { aureus, } n=38\end{array}$} & \multirow[t]{2}{*}{ OR confidence interval at $95 \%$} & \multirow[t]{2}{*}{$p$ value } \\
\hline & MRSA, $n=14$ & MSSA, $n=24$ & & \\
\hline Yes & $8(57.14 \%)$ & $04(16.67 \%)$ & \multirow{10}{*}{$6.2793[1.1926 ; 39.9359]$} & \multirow{10}{*}{0.014} \\
\hline Women's surgery & 1 & - & & \\
\hline Surgery for men & 2 & 1 & & \\
\hline Gynecology & 2 & 1 & & \\
\hline Child surgery & 3 & 2 & & \\
\hline No & $6(42.86 \%)$ & $20(83.33 \%)$ & & \\
\hline Women's surgery & 1 & 7 & & \\
\hline Surgery for men & 2 & 2 & & \\
\hline Gynecology & 1 & 7 & & \\
\hline Child surgery & 2 & 4 & & \\
\hline
\end{tabular}

TABLE 3: Antibiotic resistance profile of isolated Staphylococcus aureus strains MRSA and MSSA $(N=38)$.

\begin{tabular}{|c|c|c|c|c|}
\hline \multirow{2}{*}{ Antibiotics } & \multicolumn{2}{|c|}{ MRSA $(n=14)$} & \multicolumn{2}{|c|}{ MSSA $(n=24)$} \\
\hline & Sensitive & Resistant & Sensitive & Resistant \\
\hline Amikacin (AK) & $14(100 \%)$ & - & $24(100 \%)$ & - \\
\hline Amoxicillin + clavulanic acid (AMC) & $6(42.85 \%)$ & $8(57.14 \%)$ & $20(83.33 \%)$ & $4(16.67 \%)$ \\
\hline Amoxicillin (AX) & $5(35.71 \%))$ & $9(64.29 \%)$ & $21(87.50 \%)$ & $3(12.50 \%)$ \\
\hline Chloramphenicol (C) & $14(100 \%)$ & - & $24(100 \%)$ & - \\
\hline Ceftazidime (CAZ) & $2(14.28 \%)$ & $12(85.72 \%)$ & $15(62.50 \%)$ & $9(37.50 \%)$ \\
\hline Cefixime (CFM) & $3(21.42 \%)$ & $11(78.58 \%)$ & $16(66.67 \%)$ & $8(33.33 \%)$ \\
\hline Ciprofloxacin (CIP) & $14(100 \%)$ & - & $24(100 \%)$ & - \\
\hline Cefalexin $(\mathrm{CN})$ & $14(100 \%)$ & - & $24(100 \%)$ & - \\
\hline Ceftriaxone (CRO) & $6(42.85 \%)$ & $8(57.15 \%)$ & $19(79.17 \%)$ & $5(20.83 \%)$ \\
\hline Cefotetan (CT) & $12(85.71 \%)$ & $2(14.29 \%)$ & $24(100 \%)$ & - \\
\hline Cefotaxime (CTX) & - & $14(100 \%)$ & $18(75.00 \%)$ & $6(25.00 \%)$ \\
\hline Erythromycin (E) & $5(35.71 \%)$ & $9(64.29 \%)$ & $22(91.67 \%)$ & $2(08.33 \%)$ \\
\hline Fusidic acid $(\mathrm{F})$ & $11(78.57 \%)$ & $3(21.43 \%)$ & $24(100 \%)$ & - \\
\hline Cefoxitin (FOX) & - & $14(100 \%)$ & $19(79.17 \%)$ & $5(20.83 \%)$ \\
\hline Imipenem (IPM) & $14(100 \%)$ & - & $24(100 \%)$ & - \\
\hline Cephalotine (KF) & $2(14.28 \%)$ & $12(85.72 \%)$ & $14(58.34 \%)$ & $10(41.66 \%)$ \\
\hline Lincomycin (L) & $14(100 \%)$ & - & $24(100 \%)$ & - \\
\hline Nalidixic acid (NA) & $6(42.85 \%)$ & $08(57.15 \%)$ & $22(91.67 \%)$ & $2(08.33 \%)$ \\
\hline Ofloxacin (OFX) & $14(100 \%)$ & - & $24(100 \%)$ & - \\
\hline Oxacillin (OX) & $1(07.14 \%)$ & $13(92.86 \%)$ & $24(100 \%)$ & - \\
\hline Piperacillin (PRL) & $3(21.42 \%)$ & $11(78.58 \%)$ & $20(83.34 \%)$ & $04(16.66 \%)$ \\
\hline Rifampicin (RA) & $14(100 \%)$ & - & $24(100 \%)$ & - \\
\hline Trimethoprim-sulfametoxazole (SXT) & $14(100 \%)$ & - & $24(100 \%)$ & - \\
\hline Tetracycline (TE) & $14(100 \%)$ & $0-$ & $24(100 \%)$ & - \\
\hline Tobramycin (TOB) & $12(85.71 \%)$ & $2(14.29 \%)$ & $24(100 \%)$ & - \\
\hline Ticarcillin (TIC) & - & $14(100 \%)$ & $20(83.34 \%)$ & $4(16.66 \%)$ \\
\hline Teicoplanin (TEC) & $4(28.57 \%)$ & $12(85.73 \%)$ & $21(87.50 \%$ & $3(12.50 \%)$ \\
\hline
\end{tabular}

resistance to some antibiotics and a high sensitivity to all antibiotics at a rate of over $70 \%$. So, we can conclude that a high prevalence of multiresistance to antibiotics has been noticed for MRSA compared to MSSA which has a slight resistance to some antibiotics and a high sensitivity to all antibiotics.

\section{Discussion}

Nasal carriage is a risk factor for surgical site infections [13]. In our study, $38 \%$ of the patients have shown nasal carriers of S. aureus (31.57\% of them developed an SSI). Eventhough some studies showed lower percentages which did not reach $30 \%$, this result is similar to the results of investigations conducted in Lebanon (38.4\%) [14] and Iraq (38.5\%) [15] and higher than results reported in Ethiopia (34.58\%) [16], Netherland (26.0\%) [17], Japan (25\%) [18], Spain (20.6\%) [19], Algeria (18.3\%) [20], and a study carried out at the Mohammed V Military Training Hospital in Morocco (31\%) [9].

Concerning the patient's factors and $S$. aureus nasal porting status, a highly significant relation has been observed between $S$. aureus nasal porting and emergency admission mode $(p=0.01)$ and a highly significant relationship between nasal porting and surgical site infection $(p<0.01)$. 
These results confirm those reported by Lepelletier et al. in 2011. However, no relationship has been observed between $S$. aureus nasal porting and other patient factors.

MRSA is one of the major multiresistant organisms and represents a major public health problem in the world [21]. In our study, the MRSA rate is $14 \%$ versus $24 \%$ of MSSA, and these results differ from those found elsewhere. In fact, it differs from one country to another according to the geographical area. Hence, a rate of $33.8 \%$ was reported in Iran [22], 1.2\% in Turkey [23], 45.4\% in Cameroon [24], 6.8\% in Taiwan [25], 40\% in Egypt [26], 53.4\% in East Africa [27], and $3.4 \%$ in Japan [18]. In our study, MRSA is generally observed in patients who have recently been hospitalized and shows a significant relationship between MRSA nasal porting and the admission's mode $(p<0.05)$, which explains why patients admitted to emergency departments have a high risk of MRSA colonization.

In terms of age groups, children under 15 years have recorded a high number of MRSA, which is similar to other studies [28]. The highest MRSA carrier rate is recorded among female patients, which is contradictory to the results found at another hospital center in Morocco [9], where the MRSA carrier rate was higher in the child surgery department followed by the men surgery department. This proportion varies according to the department type and patients categories as well as according to the care type in the different departments.

For surgical site infections, a significant relationship between MRSA and surgical site infections $(p<0.05)$ has been found. This result is similar to those reported by different studies $[18,29,30]$.

Regarding antibiotic susceptibility, MRSA isolates show high resistance to ceftazidime $(85.72 \%)$, cefixime $(78.58 \%)$, erythromycin (64.29\%), Cefalotin (85.72\%), piperacillin (78.58\%), and teicoplanin (85.73\%) which means multidrug resistance. Other studies in Morocco have shown that resistance to Erythromycin and the antibiotic resistance profile varies with geographical region and changes over time [31]. Our multidrug resistance result is consistent with other studies [32,33], which is explained by the antibiotics overuse on the one hand and by patients self-medication with antibiotics on the other hand.

Nasal carriage of $S$. aureus is a well-identified factor in patients undergoing surgical procedures in surgical departments; hence, it is necessary to eradicate. In this context, some scientific studies carried out showed firstly the effectiveness of a whole body wash with a $4 \%$ chlorhexidine solution for the eradication of the MRSA strains [34] and secondly the effectiveness of the antibiotic agent mupirocin [35] in reducing the surgical site infection [35]. Furthermore, the application of decontamination procedures in preoperative patients can be difficult, especially for emergency surgery, due to the time required for diagnosis (2 days for culture) and 3 days for treatment [30].

Despite some limitations of this study concerning mainly the investigation duration, as it was conducted over a period of six months, and the limited patients' numbers (25 patients for each department), which did not enable to differentiate permanent from intermittent nasal carriage in preoperative patients; it appears that nasal carriage of $S$. aureus significantly increases the rate of nosocomial surgical site infection (SSI) after surgery and is an independent risk factor for postoperative wound infections. Therefore, regular examination is required for patients to reduce the number of spontaneous colonization of $S$. aureus and to minimize the risk of surgical site infection.

\section{Conclusion}

This study focuses on the nasal carriage of S. aureus and the importance of screening patients for MRSA. Results showed a significant relationship between MRSA and surgical site infections as well as the admission mode of patients to the hospital. Furthermore, in our study, children have been at greater risk of MRSA than other patients. Regarding antibiotic sensitivity, MRSA isolates have been found to develop multiresistance to antibiotics, which requires early detection of MRSA during patient admissions, decolonization of carrier patients, and control of antibiotic prescription in order to prevent nosocomial infections, especially SSI.

\section{Data Availability}

All data are available from the corresponding author upon kind request.

\section{Ethical Approval}

The study was ethically approved by the Fez-Meknes regional health steering committee. All information obtained from study subjects was coded to maintain confidentiality.

\section{Consent}

Consent was obtained from participants and guardians of the children prior to data collection

\section{Conflicts of Interest}

The authors declare no conflicts of interest.

\section{Acknowledgments}

Authors would like to thank the Fez-Meknes regional health directorate. They also thank the team and health professionals of the Ibn Baja Taza Provincial Hospital Center and the public health laboratory of the delegation of the Ministry of Health in Taza for their collaboration, their patience, and their precious help.

\section{References}

[1] F. Ludovic, "Les infections du site opératoire," Revue Francophone de Cicatrisation, vol. 1, no. 2, pp. 27-30, 2017.

[2] J. M. Badia, A. L. Casey, N. Petrosillo, P. M. Hudson, S. A. Mitchell, and C. Crosby, "Impact of surgical site infection on healthcare costs and patient outcomes: a systematic review in six European countries," Journal of Hospital Infection, vol. 96, no. 1, pp. 1-15, 2017. 
[3] S. Maurice, Enquête Nationale de Prévalence des Infections Nosocomiales et des traitements Anti-Infectieux en établissements de Santé, Mai-Juin 2017, Santé Publique, Paris, France, 2019, www.santepubliquefrance.fr.

[4] Ngaroua, J. E. Ngah, T. Benet, and Y. Djibrilla, "Incidence des infections du site opératoire en Afrique sub-saharienne: revue systématique et méta-analyse," Pan African Medical Journal, vol. 24, no. 1, 2016.

[5] C. D. Benedetto, "Infection du site chirurgical: facteurs de risqué, prévention, diagnostic et traitement," Maladies infectieuses, vol. 401, no. 34, pp. 1832-1839, 2013.

[6] H. F. Wertheim, D. C. Melles, M. C. Vos et al., "The role of nasal carriage in Staphylococcus aureus infections," The Lancet Infectious Diseases, vol. 5, no. 12, pp. 751-762, 2005.

[7] P. O. Verhoeven, J. Gagnaire, E. Botelho-Nevers et al., "Detection and clinical relevance of Staphylococcus aureus nasal carriage: an update," Expert Review of Anti-infective Therapy, vol. 12, no. 1, pp. 75-89, 2014.

[8] A. G. Jensen, C. H. Wachmann, K. B. Poulsen et al., "Risk factors for hospital-acquired Staphylococcus aureus bacteremia," Archives of Internal Medicine, vol. 159, no. 13, pp. 1437-1444, 1999.

[9] H. Chemsi, Y. Moutaouakkil, M. Chadli et al., "Dépistage du portage nasal du Staphylococcus aureus lors de l'admission des patients à l'hôpital militaire d'instruction Mohammed V," Journal Marocain des Sciences Médicales, vol. 19, no. 3, pp. 20-25, 2014.

[10] D. R. Mest, D. H. Wong, K. J. Shimoda, M. E. Mulligan, and S. E. Wilson, "Nasal colonization with methicillin-resistant Staphylococcus aureus on admission to the surgical intensive care unit increases the risk of infection," Anesthesia \& Analgesia, vol. 78, no. 4, pp. 644-650, 1994.

[11] Groupe de Travail Inter-Régional CCLIN, "Ouest FICHES TECHNIQUES pour le dépistage et la décolonisation des porteurs de Staphylococcus aureus résistant à la méticilline SARM," Centre de Coordination de la lutte contre les infections nosocomiales (Inter région Ouest), 2007.

[12] F. Jehl and C. Cattoen, Comité de l'Antibiogramme de la Société Française de Microbiologie, CASFM / EUCAST: Société Française de Microbiologie Ed, Paris, France, 2019.

[13] D. Lepelletier and J. C. Lucet, "Impact du dépistage et de la décontamination sur la prévention des infections du site opératoire à Staphylococcus aureus," Journal des Anti-infectieux, vol. 13, no. 4, pp. 209-216, 2011.

[14] M. A. Halablab, S. M. Hijazi, M. A. Fawzi, and G. F. Araj, "Staphylococcus aureus nasal carriage rate and associated risk factors in individuals in the community," Epidemiology and Infection, vol. 138, no. 5, pp. 702-706, 2010.

[15] A. A. Mohammed, N. R. Hussein, S. H. Arif, and S. Daniel, "Surgical site infection among patients with Staphylococcus aureus nasal carriage," International Journal of Surgery Open, vol. 24, pp. 1-7, 2020.

[16] Y. Tsige, S. Tadesse, T. G. Eyesus et al., "Prevalence of methicillin-resistant Staphylococcus aureus and associated risk factors among patients with wound infection at referral hospital, northeast Ethiopia," Journal of Pathogens, vol. 2020, p. 7, Article ID 3168325, 2020.

[17] V. Weterings, J. Veenemans, M. van Rijen, and J. Kluytmans, "Prevalence of nasal carriage of methicillin-resistant Staphylococcus aureus in patients at hospital admission in The Netherlands, 2010-2017: an observational study," Clinical Microbiology and Infections, vol. 11, no. 25, pp. 1428.e1-1428 e5, 2019.
[18] M. Nakamura, T. Shimakawa, S. Nakano et al., "Screening for nasal carriage of Staphylococcus aureus among patients scheduled to undergo orthopedic surgery: incidence of surgical site infection by nasal carriage," Journal of Orthopaedic Science, vol. 22, no. 4, pp. 778-782, 2017.

[19] X. Pelfort, A. Romero, M. Brugués, A. García, S. Gil, and A. Marrón, "Reduction of periprosthetic Staphylococcus aureus infection by preoperative screening and decolonization of nasal carriers undergoing total knee arthroplasty," Acta Orthopaedica et Traumatologica Turcica, vol. 53, no. 6, pp. 426-431, 2019.

[20] S. Ghernaout-Benchouk, "Prevalence du portage nasal de Staphylococcus Aureus: son role dans L'infection du site operatoire," Ph.D Thesis, Faculty of Medecine of B. Benzerdjeb, Aboubekr Benlkaid University, Tlemcen, Algeria, 2013.

[21] M. Goetghebeur, P. A. Landry, D. Han, and C. Vicente, "Methicillin-resistant Staphylococcus aureus: a public health issue with economic consequences," Canadian Journal of Infectious Diseases and Medical Microbiology, vol. 18, no. 1, pp. 27-34, 2007.

[22] M. Karimi, B. N. Esfahani, M. Halaji et al., "Molecular characteristics and antibiotic resistance pattern of Staphylococcus aureus nasal carriage in tertiary care hospitals of Isfahan, Iran," Le, Infezioni in Medicina, vol. 25, no. 3, pp. 234-240, 2017.

[23] M. Oguzkaya-Artan, C. Artan, and Z. Baykan, "Prevalence and risk factors for Staphylococcus aureus and methicillinresistant Staphylococcus aureus nasal carriage inpatients in a tertiary care hospital's chest clinic in Turkey," Nigerian Journal of Clinical Practice, vol. 19, no. 3, pp. 313-317, 2016.

[24] L. K. Sinda, J. N. Dinga, S. Wanji, and S. S. Koulla, "Prevalence, susceptibility testing and multi drug resistance risk factors to methicillin resistant Staphylococcus aureus in nasal carriage of hospitalized patients and medical staff in selected hospitals in Cameroon," Journal of Microbiology and Antimicrobials, vol. 12, no. 2, pp. 42-51, 2020.

[25] T.-H. Wu, C.-Y. Lee, H.-J. Yang et al., "Prevalence and molecular characteristics of methicillin-resistant Staphylococcus aureus among nasal carriage strains isolated from emergency department patients and healthcare workers in central Taiwan," Journal of Microbiology, Immunology, and Infection, vol. 52, no. 2, pp. 248-254, 2019.

[26] W. O. Elshabrawy, M. E. Zaki, and M. F. Kamel, "Genetic and phenotypic study of methicillin-resistant Staphylococcus aureus among patients and health care workers in Mansoura university hospital, Egypt," Iranian Journal of Microbiology, vol. 9, no. 2, pp. 82-88, 2017.

[27] F. K. Wangai, M. M. Masika, M. C. Maritim, and R. A. Seaton, "Methicillin-resistant Staphylococcus aureus (MRSA) in East Africa: red alert or red herring?" BMC Infectious Diseases, vol. 19, no. 1, p. 596, 2019.

[28] M. G. Sowash and A. C. Uhlemann, "Community-associated methicillin-resistant Staphylococcus aureus case studies," Methods in Molecular Biology, vol. 1085, pp. 25-69, 2014.

[29] S. Bhattacharya, K. Pal, S. Jain, S. S. Chatterjee, and J. Konar, "Surgical site infection by methicillin resistant Staphylococcus aureus-on decline?" Journal of Clinical and Diagnostic Research, vol. 10, no. 9, pp. DC32-DC36, 2016.

[30] P.-Y. Levy, M. Ollivier, M. Drancourt, D. Raoult, and J.-N. Argenson, "Relation entre portage nasal de S. aureus et infections du site opératoire en orthopédie. rôle de la contamination nasale: revue systématique et méta-analyse de la 
littérature," Revue de Chirurgie Orthopédique et Traumatologique, vol. 6, no. 99, pp. 535-542, 2013.

[31] S. Elhamzaoui, A. Benouda, F. Allali, R. Abouqual, and M. Elouennass, "Sensibilité aux antibiotiques des souches de Staphylocoques aureus isolées dans deux hôpitaux universitaires à Rabat, Morocco," Medecine et Maladies Infectieuses, vol. 39, no. 12, pp. 891-895, 2009.

[32] O. Adebola, E. Darlington Deboh, O. Gloria Timipre et al., "Antibiogram and virulence characteristics of multi-drug resistant Staphylococcus aureus from nasal cavity of healthy students of Niger delta university, Amassoma, Bayelsa state, Nigeria," Journal of Clinical \& Diagnostic Research, vol. 13, no. 7, 2019.

[33] S. J. Moyo, A. Joachim, L. Nkinda et al., "Nasal carriage of methicillin-resistant Staphylococcus aureus among health care workers in tertiary and regional hospitals in Dar Es Salam, Tanzania," International Journal of Microbiology, vol. 2018, Article ID 5058390, 7 pages, 2018.

[34] C. Wendt, S. Schinke, M. Wurttemberger, K. Oberdorfer, O. Bock-Hensley, and H. von Baum, "Value of whole-body washing with chlorhexidine for the eradication of methicillinresistant Staphylococcus aureus: a randomized, placebo-controlled, double-blind clinical trial," Infection Control \& Hospital Epidemiology, vol. 9, no. 28, pp. 1036-1043, 2007.

[35] C. Watanakunakorn, J. Brandt, P. Durkin, S. Santore, B. Bota, and C. J. Stahi, "The efficacy of mupirocin ointment and chlorhexidine body scrubs in the eradication of nasal carriage of Staphylococcus aureus among patients undergoing longterm hemodialysis," American Journal of Infection Control, vol. 3, no. 22, pp. 138-141, 1992. 